\title{
Social Inclusion and its Interrelationships with Social Cognition and Social Functioning in First-Episode Psychosis
}

\author{
Authors: Andrew Gardner ${ }^{1,4}$, Professor Sue Cotton ${ }^{1,2}$, Dr Kelly Allott ${ }^{1,2}$, Dr Kate \\ Filia $^{1,2}$, Professor Rob Hester ${ }^{3}$, Professor Eóin Killackey ${ }^{1,2}$
}

${ }^{1}$ Orygen, National Centre of Excellence in Youth Mental Health, Parkville, Australia ${ }^{2}$ Centre for Youth Mental Health, University of Melbourne, Parkville, Australia ${ }^{3}$ School of Psychological Sciences, University of Melbourne, Australia ${ }^{4}$ School of Psychological Sciences, Monash University, Australia The corresponding author is Andrew Gardner (email andrew.gardner2@monash.edu, phone number +613413952742$)$

Acknowledgments: This paper was completed while the corresponding author was receiving a Research Training Program scholarship from the Australian Government Department of Education and Training.

This is the author manuscript accepted for publication and has undergone full peer review but has not been through the copyediting, typesetting, pagination and proofreading process, which may lead to differences between this version and the Version of Record. Please cite this article as doi: 10.1111/eip.12507

This article is protected by copyright. All rights reserved. 


\begin{abstract}
Aim: People with psychosis are at risk of social exclusion. Research is needed in this area due to the lack of direct measurement of social inclusion, which becomes salient in adolescence and is relevant to first-episode psychosis (the onset of which typically occurs during or shortly after adolescence). Social inclusion may be impacted by impaired social cognition and social functioning, which are related features observed in psychosis. The aim of this study was to explore interrelationship(s) between social cognition, social functioning, and social inclusion in first-episode psychosis while controlling for symptomatology (positive, negative, and depressive symptoms) and demographic characteristics.
\end{abstract}

Methods: A series of cross-sectional hierarchical multiple regressions were conducted to examine whether: social cognition (Theory of Mind, emotion recognition) predicted social functioning; social functioning predicted social inclusion, and; whether social functioning mediated the relationship between social cognition and social inclusion in people aged 15-25 $(M=20.49, S D=2.41)$ with first-episode psychosis $(N=146)$. Age, sex, premorbid IQ, positive and negative psychotic symptoms, and depression were control variables.

Results: Poor facial emotion recognition $\left({ }^{2}=-.22, p<.05\right)$ and negative symptoms $\left({ }^{2}=-.45\right.$, $p<.001$ ) predicted lower social functioning. Role-specific social functioning (i.e., current employment) predicted greater social inclusion $\left({ }^{2}=.17, p<.05\right)$. Higher depression symptomatology predicted lower social inclusion $\left({ }^{2}=-.43, p<.001\right)$. Social functioning did not mediate the relationship between social cognition and inclusion. Psychotic symptoms were unrelated to social inclusion.

Conclusions: Employment and depression may influence social inclusion somewhat independently of psychotic symptomatology in first-episode psychosis. Inferences should be viewed with caution given this study did not involve longitudinal data.

Keywords: First-episode psychosis; schizophrenia; social inclusion; social cognition; social functioning

This article is protected by copyright. All rights reserved. 
Social inclusion is an emerging construct that researchers are seeking to better understand given evidence for its relationship to health/wellbeing (Floyd et al., 2016). Social inclusion has been defined as the experience of acceptance/belonging through opportunities to participate in valued social activities (Social Inclusion Unit, 2008). Social exclusion has been conceived as the opposite of social inclusion (Ryan \& Sartbayeva, 2011), and may be defined as the experience of loneliness/isolation in relation to an absence of the abovementioned opportunities for social participation.

People with schizophrenia are widely considered to be socially excluded (Social Exclusion Unit, 2004), yet direct measurement of social inclusion is infrequent in this population (Baumgartner \& Burns, 2014;Huxley et al., 2016). While schizophrenia represents the end point on a continuum of psychotic severity (van Os, Kenis \& Rutten, 2010), psychosis onset typically occurs during adolescence. Two-thirds of affected people experience first-episode psychosis (FEP) before 25 years-of-age (Baldwin et al., 2005; Morgan et al., 2012). Social inclusion becomes salient for young people during this phase (Blakemore \& Mills, 2014), and is a common goal for young people with psychosis (Van Schalkwyk, Davidson \& Srihari, 2015); FEP onset can disrupt the transition to adult roles and initiate social disengagement (Lau, Black \& Sturdy, 2010). The subsequent social exclusion experienced by people with FEP is not alleviated by symptomatic remission (Alvarez-Jimenez et al., 2012;Revier et al., 2015).

Compromised social functioning and social cognitive deficits are core features of psychosis (Penn et al., 1997) with implications for social inclusion. Social functioning can be defined as age-appropriate engagement in social roles (Jaracz, Górna \& Rybakowski, 2007) regardless of whether they are valued or not. Impaired social functioning is often present 
prior to psychosis onset (Addington et al., 2008), during FEP, and beyond remission (Addington et al., 2010). Evidence exists for a relationship between symptomatology and social dysfunction in psychosis (Ventura et al., 2009).

Social cognition can be defined as information processing about the self and others in social contexts (Penn, Sanna \& Roberts, 2008). Subdomains include theory of mind (ToM) and emotion recognition (Green et al., 2005). ToM involves the ability to infer one's own and other people's mental states (Bora et al., 2006). Emotion recognition involves the capacity to make emotional inferences based on the facial/vocal expressions of others (Irani et al., 2012). There are large deficits in ToM (Cohen's $d=-1.255,95 \%$ CI $[-1.441,-1.069] p<.001$ [Sprong et al., 2007]) and emotion recognition $(d=-0.91,95 \%$ CI $[-0.97,-0.84], p$ value not reported [Kohler et al., 2010]) in psychosis compared to healthy controls.

In chronic psychosis, there is meta-analytic evidence of a large mean correlation $\left(\hat{\mu}_{A}=.48\right)$ between ToM and social functioning (Fett et al., 2011), and of a relationship between emotion recognition deficits and impaired social functioning $\left(N=24,{ }^{\prime}=0.36,95 \% \mathrm{CI}\right.$ $[0.14,0.57], p<.001$ [Irani et al., 2012]). Fewer studies have examined these phenomena in FEP, where the absence of potentially confounding long-term illness effects may allow a clearer understanding of such relationships (Sullivan et al., 2013). Preliminary evidence suggests a similar association in FEP to that found in chronic populations (Horan et al., 2012). There is no research examining the impact of the relationship between social cognition and social functioning on social inclusion in psychosis. Hence it is important to examine whether this established relationship relates to social inclusion in FEP. 
The social inclusion literature is mostly qualitative/conceptual (Gingrich \& Lightman, 2015). There is little research on social inclusion in psychosis, especially regarding the role of specific illness characteristics (Killaspy et al., 2014). Social dysfunction is one such characteristic that is likely associated with social exclusion in FEP (Fisher et al., 2008). Employment may be the most important aspect of social function in psychosis (Evans \& Repper, 2000), where unemployment is the primary contributor to psychosocial disability (Killackey et al., 2006). The estimated unemployment rate in FEP is $40 \%-50 \%$, yet most people with FEP want to work (Killackey et al., 2013a). Impaired global social function, and unemployment in particular, are likely to negatively impact social inclusion in FEP (Lau et al., 2010).

Social cognition impacts the perception of inclusion (Rosenfeld, Lieberman \& Jarskog, 2011) yet also facilitates the interpersonal interactions intrinsic to social functioning (Lysaker et al, 2013;Penn et al., 1997), which in turn likely impacts social inclusion in FEP as noted above. There is emerging evidence that young people with psychosis consider social functioning to be integral to perceived social inclusion (Van Schalkwyk et al., 2015). Hence social cognition may not influence the perception of social inclusion in this population after accounting for its effect on social functioning. This suggests that social functioning may mediate the relationship between social cognition and social inclusion in FEP.

This cross-sectional study aimed to determine the relationships between social cognition (ToM and emotion recognition), social functioning, and social inclusion in people aged 15-25 with FEP. A secondary aim was to explore the impact of control variables (demographics and symptomatology) on these relationships. It is hypothesized that: (i) social cognition will positively predict social functioning; (ii) social functioning will positively 
predict social inclusion; and (iii) social functioning will mediate the relationship between social cognition and social inclusion.

\section{Method}

\section{Setting and Sample}

This study involved baseline data analysis from a randomised controlled trial of supported employment (Killackey et al., 2013a) at the Early Psychosis Prevention and Intervention Centre (EPPIC), Orygen Youth Health (a public mental health service for people aged 15-25 in the northwest of Melbourne, Australia). EPPIC clients are offered d24 months of clinical care. Clients with e 6 months remaining were eligible to participate. Participants met criteria for a Diagnostic and Statistical Manual of Mental Disorders $4^{\text {th }}$ edition - text revised (DSMIV-TR [American Psychiatric Association, 2000]) psychotic disorder.

Exclusion criteria were intellectual disability, florid psychosis, and lack of fluency in English.

\section{Measures}

\section{Social Inclusion and Social Functioning.}

The Social Inclusion Scale (SIS [Secker et al., 2009]) measures self-reported social inclusion (e.g., I have felt accepted by my neighbours, I have felt that I am playing a useful part in society, I have felt that what I do is valued by others) on Likert-type scales from 1 (Not at all) to 4 (Yes definitely). Items were summed for a score range of 16-64; higher scores indicate greater social inclusion. The SIS has demonstrated reliability and validity (Coombs, Nicholas \& Pirkis, 2013). The interviewer-rated Social and Occupational Functioning Assessment Scale (SOFAS) provides a global rating from 0-100 (Goldman, Skodol \& Lave, 1992). Higher scores indicate better functioning. The SOFAS has demonstrated reliability and validity (Hilsenroth et al., 2000;Wardenaar et al., 2013). Employment status (Currently in paid work? No/Yes) measured role-specific functioning. 


\section{Demographic and Clinical Variables.}

Demographic information included age, gender, and estimated premorbid IQ via the Wide Range Achievement Test - Fourth Edition Reading Subtest (WRAT-4 [Wilkinson \& Robertson, 2006]). Psychotic and other Axis I disorders were determined via the Structured Clinical Interview for DSM-IV-TR (SCID-IV-TR [First et al., 2001]). The Brief Psychiatric Rating Scale - Positive Symptoms subscale (BPRS-PS [Overall \& Gorham, 1962]) and the Scale for Assessment of Negative Symptoms (SANS [Andreasen, 1984]) measured positive and negative symptoms. The Center for Epidemiological Studies of Depression (CES-D [Radloff, 1977]) measured self-reported depressive symptomatology.

\section{Social Cognition.}

The False Belief and Deception Stories task has demonstrated discriminant validity as a ToM measure (Harrington, Siegert \& McClure, 2005). Participants are read stories then asked what a character was thinking and why (first-order), and what a character thought another character was thinking and why (second-order). Correct responses were given one (first-order) or two (second-order) points. Scores were summed to create total scores from 026. The Picture Sequencing Task (PST [Langdon \& Coltheart, 1999]) has demonstrated reliability and validity as a ToM measure (Bell, 2012). Participants assemble false belief comic strip cards depicting characters performing various actions. Scores were based on correct card positioning; mean scores were calculated and ranged from 0-6. The Hinting Task (Corcoran, Mercer \& Frith, 1995) is a ToM measure demonstrating strong psychometric properties (Pinkham et al., 2015). Participants are asked what a character from a story really meant by what $\mathrm{s} /$ he said. Correct responses were given a score of two; incorrect respondents were given a hint. Subsequent correct responses were given a score of one, incorrect responses a score of zero. Scores were summed to create total scores ranging from 0-20. Higher scores on all tasks indicate superior ToM. 
The Diagnostic Analysis of Nonverbal Accuracy (DANVA) - Adult Version measures emotion recognition. It has demonstrated reliability and validity (Nowicki \& Carton, 1993). The DANVA-2, Adult Facial Expressions (DANVA-2-AF) comprises 24 photographs: participants have to identify happy, sad, angry, and fearful faces. The DANVA2, Adult Paralanguage (DANVA-2-AP [Nowicki \& Duke, 1994]) comprises 24 audio recordings: participants have to identify the same emotions. On both tasks errors are summed and total scores range from 0-24. Higher scores indicate poorer emotion recognition.

\section{Procedure}

The Melbourne Health Human Research Ethics Committee approved the study (2007.648). Informed consent was obtained from participants and parents (where appropriate). From April 2009 until April 2011, 146 participants completed baseline assessments.

\section{Data Analyses}

Analyses were conducted using $\operatorname{IBM}^{\circledR}$ SPSS $^{\circledR}$ Version 22. Data were screened as per Tabachnick and Fidell (2012).

A three-block enter hierarchical multiple regression tested whether social cognition predicted social functioning while controlling for demographics and symptomatology. Demographics were entered as predictors in block one, symptomatology measures in block two, and social cognition measures in block three. The outcome variable was SOFAS score. A three-block enter hierarchical multiple regression tested whether social functioning predicted social inclusion while controlling for demographics and symptomatology. SIS score was the outcome variable. Demographics were entered as predictors in block one, symptomatology in block two, and SOFAS score in block three. A five-block enter hierarchical multiple regression using the PROCESS script (Hayes, 2013 [see Appendix]) 
tested whether social functioning mediated the relationship between social cognition and social inclusion while controlling for other variables. SIS score was the outcome variable with demographics entered as predictors in block one, symptomatology in block two, social cognition measures that predicted SOFAS score in block three, SOFAS score in block four, and employment status in block five.

\section{Results}

\section{Sample Characteristics}

Table 1 shows sample characteristics $(N=146)$. Most participants were male, unemployed, not studying, and were prescribed antipsychotic medication in the past 6 months. The most common diagnosis was schizophrenia. The mean SOFAS score $(51.47, S D=10.39)$ indicated seriously impaired social functioning. The mean SIS score $(42.14, S D=6.98)$ suggested low levels of social inclusion, as did objective indicators ( $82 \%$ not studying, 16\% undertaking paid employment). Social cognition mean scores were consistent with previous studies suggesting impaired abilities in FEP compared to controls (Thompson et al., 2012).

\section{(Insert Table 1)}

\section{Does Social Cognition Predict Social Functioning?}

Demographics were entered in block one of the hierarchical multiple regression, explaining 3\% of variance in SOFAS score. Symptomatology was entered in block two, explaining a statistically significant additional $33 \%$ of variance, $R_{\triangle}^{2}=.33, F_{\triangle}(3,139)=23.73$, $p<.001$. Social cognition was entered in block three, explaining an additional $4 \%$ of variance. The final model explained $40 \%$ of variance in SOFAS score, $R^{2}=.40$ (Adjusted $R^{2}=.35$ ), and was statistically significant, $F(11,134)=8.20, p<.001$ (see Table 2). DANVA-2-AF error score 
was a significant negative individual predictor of SOFAS score $\left({ }^{2}=-.22, p<.01\right)$. SANS score remained a significant negative predictor of SOFAS score after the inclusion of social cognitive variables, and was the strongest individual predictor in the model $\left({ }^{2}=-.45, p<.001\right)$.

(Insert Table 2)

\section{Does Social Functioning Predict Social Inclusion?}

Demographics were entered in block one of the hierarchical multiple regression, and explained $<1 \%$ of variance in SIS score. Symptomatology was entered in block two, explaining a statistically significant additional $27 \%$ of variance, $R_{\Delta}^{2}=.27, F_{\Delta}(3,139)=17.62$, $p<.001$. SOFAS score was entered in block three, explaining a statistically significant additional $3 \%$ of variance, $R_{\Delta}^{2}=.03, F_{\Delta}(1,138)=5.48, p=.03$. The final model explained $30 \%$ of variance in SIS score, $R^{2}=.30$ (Adjusted $R^{2}=.27$ ), and was statistically significant $F(7,138)=8.63, p<.001$ (see Table 3 ). SOFAS score was a significant positive individual predictor $\left({ }^{2}=.21, p=.02\right)$. CES-D score remained a significant negative predictor after the addition of SOFAS score, and was the strongest individual predictor in the model $\left(^{2}=-.41\right.$, $p<.001)$. WRAT-4 score was a significant negative individual predictor $\left({ }^{2}=-.16, p=.04\right)$.

(Insert Table 3)

\section{Does Social Functioning Mediate the Relationship between Social Cognition and Social Inclusion?}

Demographics were entered in block one of the hierarchical multiple regression and explained $<1 \%$ of variance in SIS score. Symptomatology was entered in block two, explaining a statistically significant additional $28 \%$ of variance, $R_{\Delta}^{2}=.28, F_{\Delta}(3,139)=17.62$, 
$p<.001$. DANVA-2-AF error score was entered in block three, explaining $<1 \%$ of additional variance. SOFAS score was entered in block four, explaining a statistically significant additional $3 \%$ of variance, $R_{\Delta}^{2}=.03, F_{\Delta}(1,137)=6.02, p=.02$. Employment status was entered in block five, explaining a statistically significant additional $2 \%$ of variance, $R_{\triangle}^{2}=.02$, $F_{\Delta}(1,136)=4.09, p<.05$. The final model explained $33 \%$ of variance in SIS score, $R^{2}=.33$ (Adjusted $R^{2}=.28$ ), and was statistically significant $F(9,136)=7.39, p<.001$ (see Table 4). The mediation hypothesis was not supported: neither the direct nor indirect effect of DANVA-2AF error score on SIS score was significant (see Figure 1). With the introduction of current employment, a significant positive individual predictor $\left({ }^{2}=.17, p<.05\right)$, SOFAS score no longer predicted SIS score. CES-D score remained a significant negative predictor and the strongest individual predictor in the model $\left({ }^{2}=-.43, p<.001\right)$.

(Insert Table 4)

(Insert Figure 1)

\section{Discussion}

This study is the first to explore relationships between social cognition, social functioning, and social inclusion in FEP. The previously found relationship between emotion recognition and social function in psychosis was replicated (Irani et al., 2012). Role-specific social functioning (i.e., current employment) predicted greater social inclusion, but social functioning did not mediate the relationship between social cognition and social inclusion. Higher depression symptomatology but not psychotic symptomatology predicted lower social inclusion.

\section{Social Functioning and Other Predictors of Social Inclusion}

As hypothesised, better social functioning (i.e., current employment) predicted greater social inclusion, complementing evidence that participation is a key component of subjective inclusion in FEP (Cotton et al., 2011; Ramsay et al., 2011). When employment status was 
added to the regression model, global social functioning ceased to predict social inclusion. This suggests that in FEP employment is the most important aspect of social function (Evans \& Repper, 2000). Employment explained $2 \%$ of the variance in social inclusion though, implying that factors other than social functioning make a relatively larger contribution. Also, this cross-sectional study cannot rule out a reverse relationship whereby social inclusion predicts social function.

Higher depression symptomatology predicted lower social inclusion, and was the strongest individual predictor. The level of depressive symptomatology was clinically significant and similar to other FEP studies (Killackey, Jackson \& McGorry, 2008). When compared to its relationship with other variables, the strength of association between social inclusion and depressive symptomatology raises the question of whether the former construct is actually a proxy measure of depression. There is longitudinal evidence that perceived social exclusion is related yet antecedent to depression in FEP (Iqbal et al., 2000), suggesting they may be distinct but overlapping constructs. Psychosocial interventions can prevent an acute depressive reaction to initial social losses in FEP from developing into chronic depression (Siris, 2000).

Social cognition did not predict social inclusion. The hypothesis that this proposed relationship was mediated by social functioning was not supported. Social cognitive domains other than those included may impact social inclusion. Attributional style (AS) is a subdomain characterising how people explain causes of events in their lives (Couture, Penn \& Roberts, 2006). Few studies have examined AS in FEP, but there is tentative evidence for a tendency to blame others rather than situations for negative events in this population (Fornells-Ambrojo \& Garety, 2009). AS may therefore have implications for perception of 
social inclusion and interpersonal functioning in FEP. Higher social functioning may provide opportunities for corrective feedback regarding such AS, as well as directly impacting social inclusion. Hence social functioning may mediate the relationship between AS and social inclusion in FEP.

No effect of psychotic symptoms on social inclusion was found: employment may improve social inclusion in FEP regardless of symptomatology. This compliments evidence of a divergence between symptomatic and social outcomes in FEP (Morgan et al., 2014;Revier et al., 2015) and suggests disrupted education/employment during and after FEP onset may be more relevant to social exclusion than is psychotic symptomatology (Killackey et al., 2013b). People with FEP should therefore not be denied support to pursue vocational goals based on the assumption that symptoms will interfere (Holttum, 2013). Unemployment may negatively impact social inclusion in FEP despite symptomatic recovery (Morgan et al., 2014), and people with FEP are likely to disengage if interventions do not incorporate social inclusion through vocational achievement (Van Schalkwyk et al., 2015). Interventions such as Individual Placement and Support (Killackey et al., 2013a) may contribute to improved social function and inclusion, and enhanced treatment engagement in FEP.

\section{Social Cognition}

As hypothesized poorer facial emotion recognition predicted lower social functioning, replicating previous findings (Horan et al., 2012), but vocal emotion recognition did not. Facial emotion recognition may be more pertinent to social functioning than is vocal emotion recognition in psychosis (Hooker \& Park, 2002). Negative symptomatology predicted lower social functioning, complimenting previous research (Ventura et al., 2009). Counter to prediction and previous findings (Fett et al., 2011), no ToM measure predicted social 
functioning. Emotion recognition may more reliably predict social functioning than ToM in psychosis (Couture et al., 2006).

\section{Strengths and Limitations}

The large sample allowed adequate statistical power, and a range of variables were included. However, neither the SIS nor any social inclusion measure has undergone sufficient psychometric assessment (Coombs et al., 2013). Psychometrically sound measures must be developed and domains underlying this construct identified in FEP. There is also limited psychometric data for the included social cognitive measures (Pinkham et al., 2015). There is considerable developmental variation across the 15-25 age range, which may impact the included variables. Additional informants were not available to validate self-report data. Finally, causality cannot be inferred from these cross-sectional findings.

\section{Conclusion}

Social inclusion is related to better health/wellbeing, and becomes salient in adolescence (when FEP onset typically occurs). Illness onset can impede transitions to adulthood, yet social inclusion has scarcely been researched in early psychosis. This is one of the first studies to directly examine social inclusion in FEP. Role-specific social functioning (i.e., current employment) predicted greater social inclusion, and higher depression symptomatology predicted decreased social inclusion. Social functioning did not mediate the relationship between social cognition and social inclusion. There was no evidence for a relationship between psychotic symptomatology and social inclusion. 


\section{Statement of Ethical Standards}

The Melbourne Health Human Research Ethics Committee approved this study (2007.648). Prospective participants met with study staff, who obtained written informed consent. Where appropriate, parental consent was obtained.

\section{Conflict of Interest Statement}

On behalf of all authors, the corresponding author states that there is no conflict of interest. 


\section{References}

Addington, J., Girard, T. A., Christensen, B. K., \& Addington, D. (2010). Social cognition mediates illness-related and cognitive influences on social function in patients with schizophrenia-spectrum disorders. Journal of Psychiatry and Neuroscience, 35, 49-54. doi:10.1503/jpn.080039

Addington, J., Penn, D., Woods, S. W., Addington, D., \& Perkins, D. O. (2008). Facial affect recognition in individuals at clinical high risk for psychosis. British Journal of Psychiatry, 192, 67-68. doi:10.1016/j.biotechadv.2011.08.021.Secreted

Alvarez-Jimenez, M., Gleeson, J. F., Henry, L. P., Harrigan, S. M., Harris, M. G., Killackey, E., .. \& Jackson, H. J. (2012). Road to full recovery: longitudinal relationship between symptomatic remission and psychosocial recovery in first-episode psychosis over 7.5 years. Psychological medicine, 42, 595-606.

American Psychiatric Association. (2000). Diagnostic and statistical manual of mental disorders ( $4^{\text {th }}$ ed., text revision). Washington, DC: Author

Andreasen, N.C. (1984). Scale for Assessment of Negative Symptoms (SANS). Iowa City, University of Iowa. doi: 10.1037/t12696-000

Baldwin, P., Browne, D., Scully, P. J., Quinn, J. F., Morgan, M. G., Kinsella, A., ... Waddington, J. L. (2005). Epidemiology of first-episode psychosis: Illustrating the challenges across diagnostic boundaries through the Cavan-Monaghan study at 8 years. Schizophrenia Bulletin, 31, 624-638. doi:10.1093/schbul/sbi025

Baumgartner, J. N., \& Burns, J. K. (2014). Measuring social inclusion - A key outcome in global mental health. International Journal of Epidemiology, 43, 354-364. doi:10.1093/ije/dyt224 
Bell, E. M. (2012). Operationalizing 'Theory of Mind': The psychometrics of mentalizing in schizophrenia (Thesis, Doctor of Philosophy). University of Otago. Retrieved from http://hdl.handle.net/10523/2580

Blakemore, S. J., \& Mills, K. L. (2014). Is adolescence a sensitive period for sociocultural processing? Annual review of psychology, 65, 187-207.

Bora, E., Eryavuz, A., Kayahan, B., Sungu, G., \& Veznedaroglu, B. (2006). Social functioning, theory of mind and neurocognition in outpatients with schizophrenia; mental state decoding may be a better predictor of social functioning than mental state reasoning. Psychiatry Research, 145, 95-103. doi:10.1016/j.psychres.2005.11.003

Coombs, T., Nicholas, A., \& Pirkis, J. (2013). A review of social inclusion measures. The Australian and New Zealand Journal of Psychiatry, 47, 906-19. doi:10.1177/0004867413491161

Corcoran, R., Mercer, G., \& Frith, C.D. (1995). Schizophrenia, symptomatology and social inference: investigating "theory of mind" in people with schizophrenia. Schizophrenia Research, 17, 5-13. doi: 10.1016/0920-9964(95)00024-G

Cotton, S. M., Luxmoore, M., Woodhead, G., Albiston, D. D., Gleeson, J. F., \& McGorry, P. D. (2011). Group programmes in early intervention services. Early intervention in Psychiatry, 5, 259-266.

Couture, S. M., Penn, D. L., \& Roberts, D. L. (2006). The functional significance of social cognition in schizophrenia: A review. Schizophrenia Bulletin, 32, S44-63. doi:10.1093/schbul/sb1029

Evans, J., \& Repper, J. (2000). Employment, social inclusion and mental health. Journal of psychiatric and mental health nursing, 7, 15-24.

Fett, A. K. J., Viechtbauer, W., Penn, D. L., van Os, J., \& Krabbendam, L. (2011). The relationship between neurocognition and social cognition with functional outcomes in 
schizophrenia: a meta-analysis. Neuroscience \& Biobehavioral Reviews, 35, 573-588. doi: 10.1016/j.neubiorev.2010.07.001

First, M.B., Spitzer, R.L., Gibbon, M., \& Williams, J.B.W. (2001). Structured Clinical Interview for DSM-IV-TR Axis I Disorders - Patient Edition (SCID-I/P, 2/2001 Revision). New York, Biometrics Research Department, New York State Psychiatric Institute, 2001.

Fisher, H., Theodore, K., Power, P., Chisholm, B., Fuller, J., Marlowe, K., ... \& Johnson, S. (2008). Routine evaluation in first episode psychosis services: Feasibility and results from the MiData project. Social Psychiatry and Psychiatric Epidemiology, 43, 960-967. doi: $10.1007 \% 2 F s 00127-008-0386-1$

Floyd, K., Veksler, A. E., McEwan, B., Hesse, C., Boren, J. P., Dinsmore, D. R., \& Pavlich, C. A. (2016). Social Inclusion Predicts Lower Blood Glucose and Low-Density Lipoproteins in Healthy Adults. Health Communication, 1-4.

Fornells-Ambrojo, M., \& Garety, P. A. (2009). Understanding attributional biases, emotions and self-esteem in poor me paranoia: findings from an early psychosis sample. British Journal of Clinical Psychology, 48, 141-162.

Gingrich, L. G., \& Lightman, N. (2015). The empirical measurement of a theoretical concept: Tracing social exclusion among racial minority and migrant groups in Canada. Social Inclusion, 3, 98-111.

Goldman, H. H., Skodol, A.E., \& Lave, T. R. (1992). Revising Axis V for DSM-IV: A review of measures of social functioning. American Journal of Psychiatry, 149, 11481156. doi:10.1176/ajp.149.9.1148

Green, M. F., Olivier, B., Crawley, J. N., Penn, D. L., \& Silverstein, S. (2005). Social cognition in schizophrenia: Recommendations from the measurement and treatment 
research to improve cognition in schizophrenia new approaches conference. Schizophrenia Bulletin, 31, 882-887. doi:10.1093/schbul/sbi049

Harrington, L., Siegert, R., \& McClure, J. (2005). Theory of mind in schizophrenia: A critical review. Cognitive Neuropsychiatry, 10, 249-286. doi: 10.1080/13546800444000056

Hayes, A. F. (2013). Introduction to mediation, moderation, and conditional process analysis: A regression-based approach. Guilford Press.

Hilsenroth, M. J., Ackerman, S. J., Blagys, M. D., Baumann, B. D., Baity, M. R., Smith, S. R., ... \& Holdwick Jr, D. J. (2000). Reliability and validity of DSM-IV axis V. American Journal of Psychiatry, 157, 1858-1863. doi: 10.1176/appi.ajp.157.11.1858

Holttum, S. (2013). Improving social inclusion for young people diagnosed with "first episode psychosis": Employment, education and online support. Mental Health and Social Inclusion, 17, 112-117. doi: 10.1108/mhsi-05-2013-0016

Hooker, C., \& Park, S. (2002). Emotion processing and its relationship to social functioning in schizophrenia patients. Psychiatry Research, 112(1), 41-50.

Horan, W. P., Green, M. F., Degroot, M., Fiske, A., Hellemann, G., Kee, K., ... Nuechterlein, K. H. (2012). Social cognition in schizophrenia, part 2: 12-month stability and prediction of functional outcome in first-episode patients. Schizophrenia Bulletin, 38, 865-872. doi:10.1093/schbul/sbr001

Huxley, P. J., Chan, K., Chiu, M., Ma, Y., Gaze, S., \& Evans, S. (2016). The social and community opportunities profile social inclusion measure: Structural equivalence and differential item functioning in community mental health residents in Hong Kong and the United Kingdom. International Journal of Social Psychiatry, 62, 133-140.

Irani, F., Seligman, S., Kamath, V., Kohler, C., \& Gur, R. (2012). A meta-analysis of emotion perception and functional outcomes in schizophrenia. Schizophrenia Research, 137, 203-211. doi:10.1016/j.schres.2012.01.023 
Iqbal, Z., Birchwood, M., Chadwick, P., \& Trower, P. (2000). Cognitive approach to depression and suicidal thinking in psychosis. 2 . Testing the validity of a social ranking model. British Journal of Psychiatry, 177(522-528).

Jaracz, K., Górna, K., \& Rybakowski, F. (2007). Social functioning in first-episode schizophrenia: A prospective follow-up study. Archives of Psychiatry and Psychotherapy, 4, 19-27. doi: http://dx.doi.org/10.1016/S0924-9338(10)71168-8

Killackey, E., Allott, K., Cotton, S. M., Jackson, H., Scutella, R., Tseng, Y. P., ... \& McGorry, P. D. (2013a). A randomized controlled trial of vocational intervention for young people with first-episode psychosis: Method. Early Intervention in Psychiatry, 7, 329-337. doi: 10.1111/eip.12066

Killackey, E., Alvarez-Jimenez, M., Allott, K., Bendall, S., \& McGorry, P. (2013b). Community rehabilitation and psychosocial interventions for psychotic disorders in youth. Child and adolescent psychiatric clinics of North America, 22, 745-758.

Killackey, E., Jackson, H.J., Gleeson, J., Hickie, I.B., McGorry, P.D. (2006). Exciting career opportunity beckons! Early intervention and vocational rehabilitation in first episode psychosis: employing cautious optimism. Australian and New Zealand Journal of Psychiatry, 40, 951-962

Killackey, E., Jackson, H.J., \& McGorry, P.D. (2008). Vocational intervention in firstepisode psychosis: individual placement and support v. treatment as usual. The British Journal of Psychiatry, 193, 114-120.

Killaspy, H., White, S., Lalvani, N., Berg, R., Thachil, A., Kallumpuram, S., .. Mezey, G. (2014). The impact of psychosis on social inclusion and associated factors. International Journal of Social Psychiatry, 60, 148-154. doi:10.1177/0020764012471918 
Kohler, C. G., Walker, J. B., Martin, E. A., Healey, K. M., \& Moberg, P. J. (2010). Facial emotion perception in schizophrenia: A meta-analytic review. Schizophrenia Bulletin, 36, 1009-19. doi:10.1093/schbul/sbn192

Langdon, R. \& Coltheart, M. (1999). Mentalising, schizotypy, and schizophrenia. Cognition, 71, 43-71. doi: 10.1016/S0010-0277(99)00018-9

Lau, A., Black, A., \& Sturdy, V. (2010). Social inclusion and recovery for young people with first episode psychosis: A London survey of early intervention in psychosis teams and their links with the further education system. Mental Health and Social Inclusion, 14, 11-19. doi: 10.5042/mhsi.2010.0065

Lysaker, P. H., Vohs, J. L., Ballard, R., Fogley, R., Salvatore, G., Popolo, R., \& Dimaggio, G. (2013). Metacognition, self-reflection and recovery in schizophrenia. Future Neurology, 8, 103-115. doi:10.2217/fnl.12.78

Morgan, C., Lappin, J., Heslin, M., Donoghue, K., Lomas, B., Reininghaus, U., ... \& Dazzan, P. (2014). Reappraising the long-term course and outcome of psychotic disorders: The AESOP-10 study. Psychological Medicine, 44, 2713-2726. doi:

$10.1017 / \mathrm{S} 0033291714000282$

Morgan, V. A, Waterreus, A., Jablensky, A., Mackinnon, A., Mcgrath, J. J., Carr, V., ... Saw, S. (2012). People living with psychotic illness 2010: Second Australian national survey. Australian and New Zealand Journal of Psychiatry, 46, 735-752. doi: $10.1177 / 0004867412449877$

Nowicki, S. \& Carton, J. (1993). The measurement of emotional intensity from facial expressions: the DANVA Faces 2. Journal of Social Psychology, 133, 749-750.

Nowicki, S. \& Duke, M.P. (1994). Individual differences in the nonverbal communication of affect: the Diagnostic Analysis of Nonverbal Accuracy scale. Journal of Nonverbal Behavior, 18, 9-35. doi:10.1007/bf02169077 
Overall, J.E. \& Gorham, D.R. (1962). The Brief Psychiatric Rating Scale. Psychiatic Reports, 10, 799-812. doi:10.2466/pr0.1962.10.3.799

Penn, D. L., Corrigan, P. W., Bentall, R. P., Racenstein, J., \& Newman, L. (1997). Social cognition in schizophrenia. Psychological Bulletin, 121, 114-132. doi:10.1037/00332909.121.1.114

Penn, D. L., Sanna, L. J., \& Roberts, D. L. (2008). Social cognition in schizophrenia: An overview. Schizophrenia Bulletin, 34, 408-411. doi:10.1093/schbul/sbn014

Pinkham, A. E., Penn, D. L., Green, M. F., \& Harvey, P. D. (2015). Social cognition psychometric evaluation: Results of the initial psychometric study. Schizophrenia bulletin, sbv056. doi: 10.1093/schbul/sbv056

Radloff, L.S. (1977). The CES-D Scale: A self-report depression scale for research in the general population. Applied Psychological Measurement, 1, 385-401. doi:

$10.1177 / 014662167700100306$

Ramsay, C. E., Broussard, B., Goulding, S. M., Cristofaro, S., Hall, D., Kaslow, N. J., ... Compton, M. T. (2011). Life and treatment goals of individuals hospitalized for firstepisode nonaffective psychosis. Psychiatry Research, 189, 344-348. doi:10.1016/j.psychres.2011.05.039

Revier, C. J., Reininghaus, U., Dutta, R., Fearon, P., Murray, R. M., Doody, G. A., ... \& Jones, P. B. (2015). Ten-year outcomes of first-episode psychoses in the MRC ÆSOP-10 study. The Journal of Nervous and Mental disease, 203, 379-386. doi:

10.1097/nmd.0000000000000295

Rosenfeld, A. J., Lieberman, J. a, \& Jarskog, L. F. (2011). Oxytocin, dopamine, and the amygdala: A neurofunctional model of social cognitive deficits in schizophrenia. Schizophrenia Bulletin, 37, 1077-87. doi:10.1093/schbul/sbq015 
Ryan, C. \& Sartbayeva, A. (2011). Young Australians and social inclusion. Available at SSRN 2012859. Retrieved from https://papers.ssrn.com/sol3/papers.cfm?abstract_id=2012859

Secker, J., Hacking, S., Kent, L., Shenton, J., \& Spandler, H. (2009). Development of a measure of social inclusion for arts and mental health project participants. Journal of Mental Health, 18, 65-72. doi:10.1080/09638230701677803

Siris, S. G. (2000). Depression in schizophrenia: Perspective in the era of "atypical" antipsychotic agents. American Journal of Psychiatry, 157, 1379-1389. doi: 10.1176/appi.ajp.157.9.1379

Social Exclusion Unit (2004). Mental health and social exclusion. London, England. Social Inclusion Unit (2008). Principles for social inclusion-everyone’s job. Australian Social Inclusion Board. Canberra: Commonwealth of Australia. Retrieved from http://pandora.nla.gov.au/pan/142909/201309201300/www.socialinclusion.gov.au/sites/default/files/publications/pdf/social-inclusionprinciples_0.pdf.

Sprong, M., Schothorst, P., Vos, E., Hox, J., \& Van Engeland, H. (2007). Theory of mind in schizophrenia: Meta-analysis. British Journal of Psychiatry, 191, 5-13. doi:10.1192/bjp.bp.107.035899

Sullivan, S., Herzig, D., Mohr, C., Lewis, G., Corcoran, R., Drake, R., \& Evans, J. (2013). Theory of mind and social functioning in first episode psychosis. Cognitive Neuropsychiatry, 18, 219-242. doi:10.1080/13546805.2012.698239

Tabachnick, B. G. \& Fidell, L. S. (2012). Using multivariate statistics (6 ${ }^{\text {th }}$ Ed.). Essex, United Kingdom: Pearson. 
Thompson, A., Papas, A., Bartholomeusz, C., Allott, K., Amminger, G. P., Nelson, B., ... \& Yung, A. (2012). Social cognition in clinical "at risk" for psychosis and first episode psychosis populations. Schizophrenia Research, 141(2), 204-209.

Van Os, J., Kenis, G., \& Rutten, B. P. F. (2010). The environment and schizophrenia. Nature, 468, 203-212. doi:10.1038/nature09563

Van Schalkwyk, G. I., Davidson, L., \& Srihari, V. (2015). Too late and too little: Narratives of treatment disconnect in early psychosis. Psychiatric Quarterly, 1-12. doi: $10.1007 / \mathrm{s} 11126-015-9348-4$

Ventura, J., Hellemann, G. S., Thames, A. D., Koellner, V., \& Nuechterlein, K. H. (2009). Symptoms as mediators of the relationship between neurocognition and functional outcome in schizophrenia: A meta-analysis. Schizophrenia Research, 113, 189-199. doi: 10.1016/j.schres.2009.03.035

Wardenaar, K. J., Wigman, J. T., Lin, A., Killackey, E., Collip, D., Wood, S. J., ... \& Yung, A. R. (2013). Development and validation of a new measure of everyday adolescent functioning: the multidimensional adolescent functioning scale. Journal of Adolescent Health, 52, 195-200. doi: 10.1016/j.jadohealth.2012.06.021

Wilkinson, G.S. \& Robertson, G.J. (2006). WRAT-4: Wide Range Achievement Test. Professional Manual. Lutz, FL: Psychological Assessment Resources, Inc. doi: $10.1177 / 0034355208320076$ 


\section{Tables}

Table 1

Demographic, clinical, illness, and social characteristics of first-episode psychosis participants

\begin{tabular}{|c|c|c|c|c|c|}
\hline Characteristic & & Total sample $(N=146)$ & & Minimum & Maximum \\
\hline & Gender ( $\%$ female $)$ & $\%(n)$ & $30.82(45)$ & & \\
\hline & Age in years & $M(S D)$ & $20.49(2.41)$ & 15 & 25 \\
\hline \multicolumn{6}{|c|}{ Estimated premorbid IQ } \\
\hline \multicolumn{6}{|c|}{ Marital Status } \\
\hline & Never married & $\%(n)$ & $97.30(142)$ & & \\
\hline \multicolumn{6}{|c|}{ Country of birth } \\
\hline \multicolumn{6}{|c|}{ Current study status } \\
\hline & Not studying & $\%(n)$ & $82.20(120)$ & & \\
\hline
\end{tabular}

This article is protected by copyright. All rights reserved. 


\begin{tabular}{|c|c|c|c|c|}
\hline Characteristic & Total sample $(N=146)$ & & Minimum & Maximum \\
\hline Years 7-9 & $\%(n)$ & $22.60(33)$ & & \\
\hline Year 10 & $\%(n)$ & $18.5(27)$ & & \\
\hline VCE/VCAL & $\%(n)$ & $40.40(59)$ & & \\
\hline \multicolumn{5}{|l|}{ Employment } \\
\hline Age at first job & $M(S D)$ & $15.70(2.11)$ & 10 & 23 \\
\hline Schizophrenia & $\%(n)$ & $38.36(56)$ & & \\
\hline Depression with Psychotic Features & $\%(n)$ & $14.38(21)$ & & \\
\hline Schizoaffective Disorder & $\%(n)$ & $13.01(19)$ & & \\
\hline Psychosis Not Otherwise Specified & $\%(n)$ & $11.64(17)$ & & \\
\hline Bipolar Disorder with Psychotic Features & $\%(n)$ & $10.96(16)$ & & \\
\hline
\end{tabular}




\begin{tabular}{|c|c|c|c|c|}
\hline Characteristic & Total sample $(N=146)$ & & Minimum & Maximum \\
\hline Brief Psychotic Disorder & $\%(n)$ & $0.68(1)$ & & \\
\hline \multicolumn{5}{|l|}{ Duration of illness (months) } \\
\hline Time in service & $M(S D)$ & $8.52(6.34)$ & 0 & 36 \\
\hline \multicolumn{5}{|l|}{ Psychopathology } \\
\hline BPRS-PS & $M(S D)$ & $8.53(4.38)$ & 4 & 20 \\
\hline \multicolumn{5}{|l|}{ Medication } \\
\hline \multicolumn{5}{|l|}{ Last 6 months prescribed: } \\
\hline Antipsychotic & $\%(n)$ & $86.30(126)$ & & \\
\hline Other psychotropic & $\%(n)$ & $39.04(57)$ & & \\
\hline Social Cognition & & & & \\
\hline
\end{tabular}




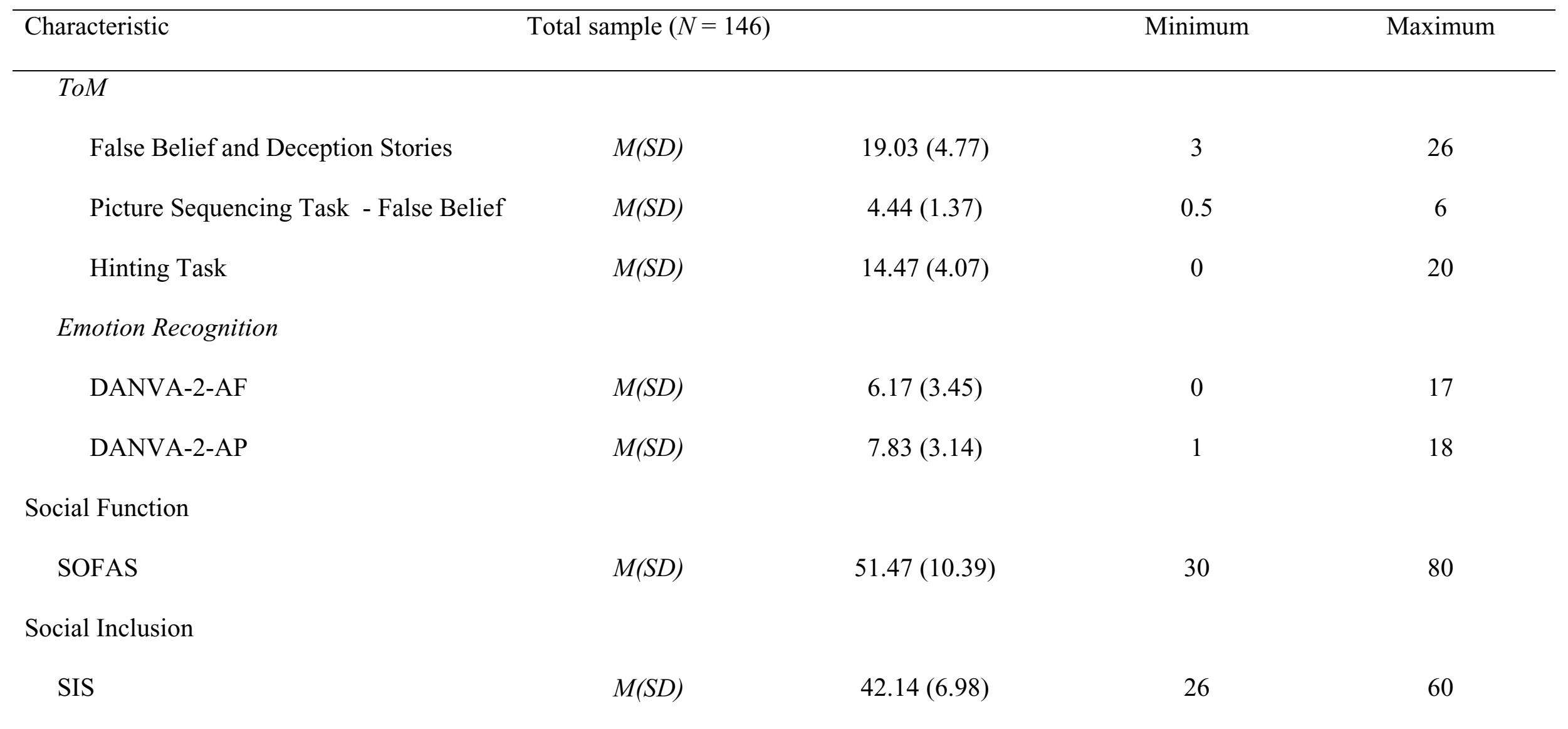

Note. $M=$ mean; $S D$ = standard deviation; $n=$ number of participants; Minimum = minimum value; Maximum = Maximum value; WRAT-4 = Wide Ranging Achievement Test Reading Subtest standardized scores; BPRS-PS = Brief Psychiatric Rating Scale Psychotic Subscale score; SANS = Scale for the Assessment of Negative Symptoms score; CES-D = Centre for Epidemiological Studies - Depression Scale score; VCE = Victorian Certificate of Education; VCAL = Victorian Certificate of Applied Learning; ToM = Theory of Mind; DANVA-2-AF = Diagnostic Analysis of Nonverbal Accuracy - Adult Facial Expressions error score; DANVA-2-AP = Diagnostic Analysis of Nonverbal Accuracy - Adult Paralanguage error score; SOFAS = Social and

Occupational Functioning Assessment Scale score; SIS = Social Inclusion Scale total score 
Table 2

Summary of the enter hierarchical multiple regression model with SOFAS score as the outcome variable and demographics entered in block one, symptomatology entered in block two, and social cognition measures entered in block three as predictor variables

\begin{tabular}{|c|c|c|c|c|c|c|c|c|}
\hline \multicolumn{9}{|c|}{ Unstandardized } \\
\hline & Predictor Variable & 2 & $\mathrm{~b}$ & $\mathrm{SE}_{\mathrm{b}}$ & $95 \% \mathrm{CI}$ for $\mathrm{b}$ & $t$ & $R^{2}$ & $R^{2}$ \\
\hline \multirow[t]{4}{*}{ Block 1} & & & & & & & .03 & .03 \\
\hline & Gender & .04 & .82 & 1.90 & {$[-2.94,4.58]$} & 0.43 & & \\
\hline & Age & -.09 & -.40 & 0.37 & {$[-1.12,0.33]$} & -1.09 & & \\
\hline & WRAT-4 & .14 & .11 & 0.06 & {$[-.02, .23]$} & 1.71 & & \\
\hline \multirow[t]{7}{*}{ Block 2} & & & & & & & .36 & .33 \\
\hline & Gender & .03 & .56 & 1.57 & {$[-2.54,3.66]$} & 0.36 & & \\
\hline & Age & -.10 & -.45 & 0.30 & {$[-1.04,0.15]$} & -1.49 & & \\
\hline & WRAT-4 & -.02 & -.01 & 0.05 & {$[-0.12,0.09]$} & -0.26 & & \\
\hline & BPRS-PS & -.13 & -.30 & 0.21 & {$[-0.71,0.11]$} & -1.44 & & \\
\hline & SANS & -.47 & -.39 & 0.07 & {$[-0.52,-0.27]$} & $-6.08 * * *$ & & \\
\hline & CES-D & -.15 & -.14 & 0.08 & {$[-0.29,0.01]$} & -1.90 & & \\
\hline \multirow[t]{5}{*}{ Block 3} & & & & & & & .40 & .04 \\
\hline & Gender & -.01 & -.15 & 1.60 & {$[-3.31,3.01]$} & -0.10 & & \\
\hline & Age & -.10 & -.42 & 0.30 & {$[-1.01,0.18]$} & -1.38 & & \\
\hline & WRAT-4 & $<-.01$ & $<-.01$ & 0.06 & {$[-0.12,0.12]$} & -.03 & & \\
\hline & BPRS-PS & -.17 & -.40 & 0.21 & {$[-0.81,0.01]$} & -1.91 & & \\
\hline
\end{tabular}

This article is protected by copyright. All rights reserved. 


\begin{tabular}{rcccccc}
\hline \multicolumn{7}{c}{ Unstandardized } \\
Predictor Variable & 2 & $\mathrm{~b}$ & $\mathrm{SE}_{\mathrm{b}}$ & $95 \% \mathrm{CI}$ for b & $t$ & $R^{2}$ \\
\hline SANS & -.45 & -.38 & 0.07 & {$[-0.51,-0.25]$} & $-5.69 * * *$ \\
CES-D & -.15 & -.15 & 0.08 & {$[-0.30,<.01]$} & -1.94 \\
Stories & -.10 & -.21 & 0.20 & {$[-0.60,0.17]$} & -1.09 \\
Hinting & -.01 & -.01 & 0.23 & {$[-0.47,0.45]$} & -.06 \\
PSFB & -.10 & -.74 & 0.60 & {$[-1.92,0.44]$} & -1.24 \\
DANVA-2-AF & -.22 & -.66 & 0.25 & {$[-1.14,-0.17]$} & $-2.67 * *$ \\
DANVA-2-AP & .02 & .07 & 0.29 & {$[-0.49,0.64]$} & 0.26
\end{tabular}

Note. Outcome variable $=$ Social and Occupational Functioning Assessment Scale (SOFAS) scores; $N=146$; WRAT-4 = Wide Ranging Achievement Test Reading Subtest scores; BPRS-PS = Brief Psychiatric Rating Scale Psychotic Subscale scores; SANS = Scale for the Assessment of Negative Symptoms scores; CES-D = Centre for Epidemiological Studies - Depression Scale scores; Stories $=$ False Belief and Deception Stories scores; Hinting $=$ Hinting Task scores; PSFB $=$ Picture Sequencing False Belief mean scores; DANVA-2-AF $=$ Adult Facial Expressions error scores; DANVA-2-AP = Adult Paralanguage error scores; ${ }^{2}=$ standardized regression coefficient; $\mathrm{b}=$ unstandardized regression coefficient; $\mathrm{SE}_{\mathrm{b}}=$ standard error for unstandardized regression coefficient; $95 \% \mathrm{CI}$ for $\mathrm{b}=95 \%$ confidence interval for unstandardized regression coefficients; $t=\mathrm{t}$-score; $R^{2}=$ strength of model prediction; $R^{2}=$ change in strength of model prediction.

$* *=p<.01 ; * * *=p<.001$ 
Table 3

Summary of the enter hierarchical multiple regression model with SIS score as the outcome variable and demographics entered in block one, symptomatology entered in block two, and SOFAS score entered in block three as predictor variables

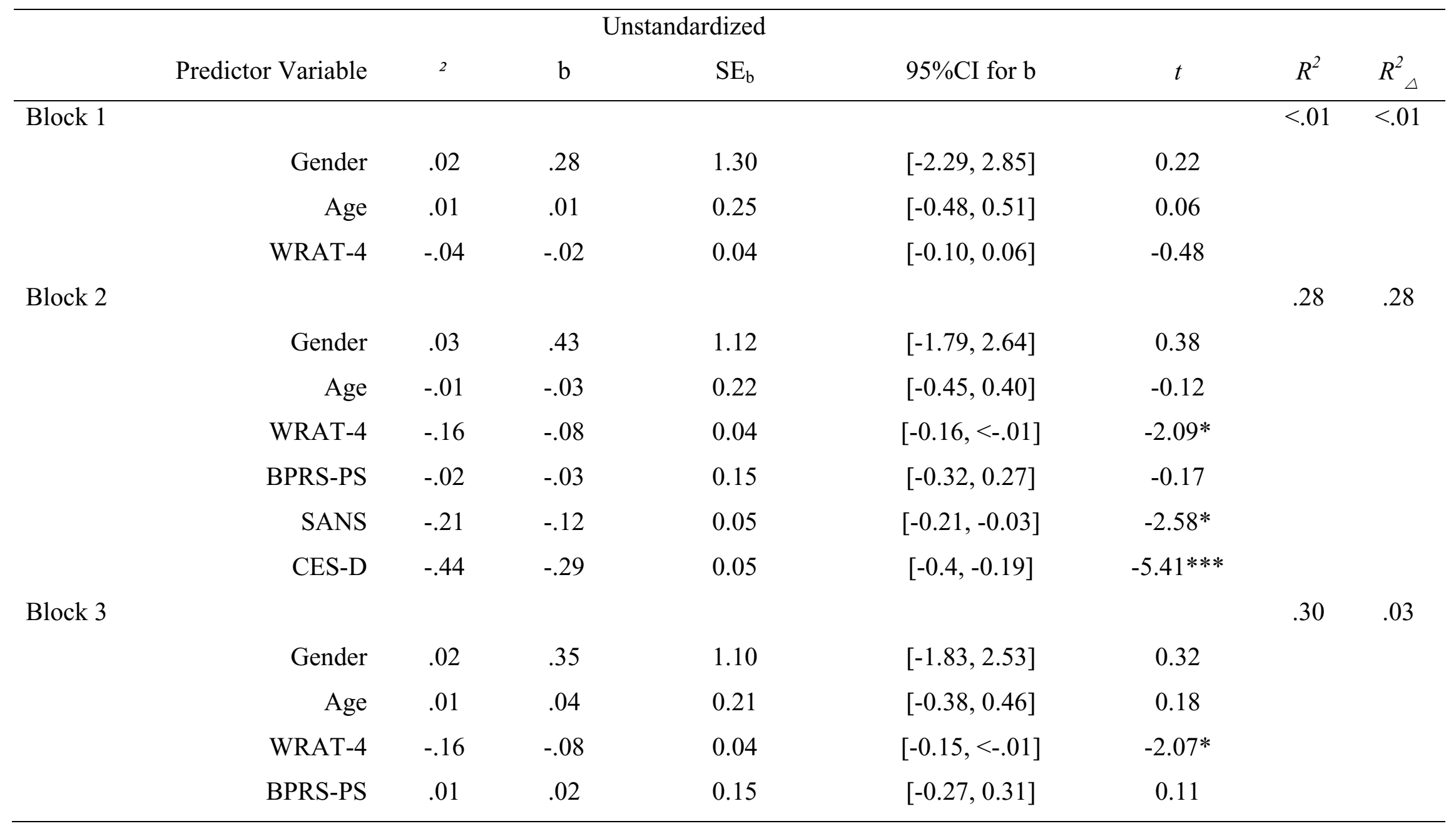




\begin{tabular}{rcccccc}
\hline & \multicolumn{3}{c}{ Unstandardized } \\
Predictor Variable & 2 & $\mathrm{~b}$ & $\mathrm{SE}$ & $95 \% \mathrm{CI}$ for b & $R_{\Delta}$ \\
\hline SANS & -.11 & -.06 & 0.05 & {$[-0.17, .04]$} & -1.26 \\
CES-D & -.41 & -.27 & 0.05 & {$[-0.38,-0.17]$} & $-5.05 * * *$ \\
SOFAS & .21 & .14 & 0.06 & {$[0.02,0.26]$} & $2.34^{*}$
\end{tabular}

Note. Outcome variable = Social Inclusion Scale (SIS) score; $N=146$; WRAT-4 = Wide Ranging Achievement Test Reading Subtest scores; BPRS-PS = Brief Psychiatric Rating Scale Psychotic Subscale scores; SANS = Scale for the Assessment of Negative Symptoms scores; CES-D = Centre for Epidemiological Studies - Depression Scale scores; SOFAS = Social and Occupational Functioning Assessment Scale scores; ${ }^{2}=$ standardized regression coefficient; $\mathrm{b}=$ unstandardized regression coefficient; $\mathrm{SE} \mathrm{b}_{\mathrm{b}}=$ standard error for unstandardized regression coefficient; $95 \% \mathrm{CI}$ for $\mathrm{b}=95 \%$ confidence interval for unstandardized regression coefficients; $t=\mathrm{t}$-score; $R^{2}=$ strength of model prediction; $R_{\Delta}^{2}=$ change in strength of model prediction $*=p<.05 ; * *=p<.01 ; * * *=p<.001$ 
Table 4

Summary of the mediation enter hierarchical multiple regression with SIS score as the outcome variable, DANVA-2-AF error score as the predictor variable, SOFAS score as the mediator variable, and demographics, symptomatology, and current employment status as control variables

\begin{tabular}{|c|c|c|c|c|c|c|c|c|}
\hline \multicolumn{9}{|c|}{ Unstandardized } \\
\hline & Predictor Variable & 2 & $\mathrm{~b}$ & $\mathrm{SE}_{\mathrm{b}}$ & $95 \% \mathrm{CI}$ for $\mathrm{b}$ & $t$ & $R^{2}$ & $R_{\Delta}^{2}$ \\
\hline \multirow[t]{4}{*}{ Block 1} & & & & & & & $<.01$ & $<.01$ \\
\hline & Gender & .02 & .28 & 1.30 & {$[-2.29,2.85]$} & 0.22 & & \\
\hline & Age & .01 & .01 & 0.25 & {$[-0.48,0.51]$} & 0.06 & & \\
\hline & WRAT-4 & -.04 & -.02 & 0.04 & {$[-0.10,0.06]$} & -0.48 & & \\
\hline \multirow[t]{7}{*}{ Block 2} & & & & & & & .28 & .28 \\
\hline & Gender & .03 & .43 & 1.12 & {$[-1.79,2.64]$} & 0.38 & & \\
\hline & Age & -.01 & -.03 & 0.22 & {$[-0.45,0.40]$} & -0.12 & & \\
\hline & WRAT-4 & -.16 & -.08 & 0.04 & {$[-0.16,<-.01]$} & $-2.09 *$ & & \\
\hline & BPRS-PS & -.02 & -.03 & 0.15 & {$[-0.32,0.27]$} & -0.17 & & \\
\hline & SANS & -.21 & -.12 & 0.05 & {$[-0.21,-0.03]$} & $-2.58 *$ & & \\
\hline & CES-D & -.44 & -.29 & 0.05 & {$[-0.4,-0.19]$} & $-5.41 * * *$ & & \\
\hline \multirow[t]{5}{*}{ Block 3} & & & & & & & .28 & $<.01$ \\
\hline & Gender & .03 & 0.49 & 1.14 & {$[-1.75,2.74]$} & 0.43 & & \\
\hline & Age & -.01 & -0.03 & 0.22 & {$[-0.46,0.39]$} & 0.16 & & \\
\hline & WRAT-4 & -.15 & -.08 & 0.04 & {$[-0.15,<0.01]$} & -1.94 & & \\
\hline & BPRS-PS & -.02 & -0.02 & 0.15 & {$[-0.32,0.27]$} & -0.16 & & \\
\hline
\end{tabular}




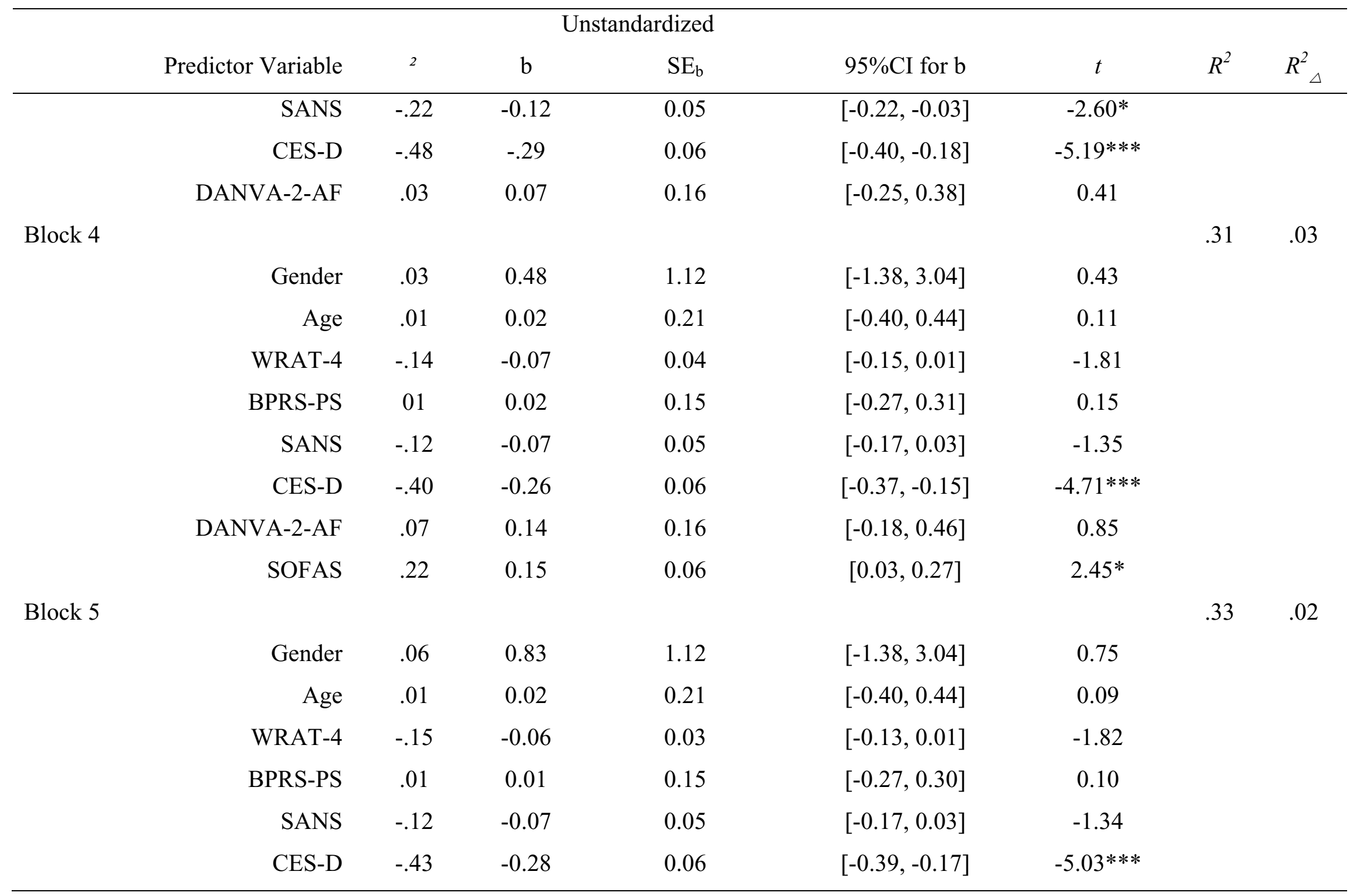




\begin{tabular}{rcccccc}
\hline & \multicolumn{5}{c}{ Unstandardized } \\
Predictor Variable & 2 & $\mathrm{~b}$ & $\mathrm{SE}_{\mathrm{b}}$ & $95 \% \mathrm{CI}$ for b & $R^{2}$ & $R_{\Delta}^{2}$ \\
\hline DANVA-2-AF & .07 & 0.13 & 0.16 & {$[-0.18,0.45]$} & 0.83 \\
SOFAS & .14 & 0.09 & 0.07 & {$[-0.04,0.22]$} & 1.42 & $2.02 *$
\end{tabular}

Note. Outcome variable = Social Inclusion Scale (SIS) score; $N=146$; WRAT-4 = Wide Ranging Achievement Test Reading Subtest score; BPRS-PS = Brief Psychiatric Rating Scale Psychotic Subscale score; SANS = Scale for the Assessment of Negative Symptoms score; CES-D = Centre for Epidemiological Studies - Depression Scale score; SOFAS = Social and

Occupational Functioning Assessment Scale score; DANVA-2-AF = Adult Facial Expressions error score; ${ }^{2}=$ standardized regression coefficient; $b=$ unstandardized regression coefficient; $\mathrm{SE}_{\mathrm{b}}$ $=$ standard error for unstandardized regression coefficient; $95 \% \mathrm{CI}$ for $\mathrm{b}=95 \%$ confidence interval for unstandardized regression coefficients; $t=\mathrm{t}$-score.

$*=p<.05 ; * * *=p<.001$ 


\section{Appendix: details of the PROCESS script for mediation analysis}

A conditional process approach to mediation analysis aims to explore the direct and indirect pathways via which variable $X$ may transfer its effect on variable $Y$ through an intermediate variable $M$. The PROCESS script (Hayes, 2013) can be used as an add-on that is implemented via syntax in SPSS. It uses an ordinary least squares regression approach to path analysis, which enables the estimation of direct and indirect effects in mediator models. One advantage of using the PROCESS script is that it uses sampling with replacement to generate a user-defined number of bootstrapped samples of confidence intervals around the indirect effect of $X$ on $Y$ through $M$. The default number of bootstrap samples is 1,000 but the researcher can specify this number. This removes the need to make assumptions about the shape of the sampling distribution of the indirect effect. The official documentation for the PROCESS script (and a full description of how it may be implemented in mediation and moderation hypotheses) can be found in the Introduction to Mediation, Moderation, and Conditional Process Analysis book by Hayes (2013). 
Figure 1. Direct and indirect effects of DANVA-2-AF error score on SIS score via SOFAS score while controlling for other variables

Note. $N=146$; DANVA-2-AF = Adult Facial Expressions error score; SOFAS = Social and Occupational Functioning Assessment Scale score; Social Inclusion Scale (SIS) score; WRAT-4 = Wide Ranging Achievement Test Reading Subtest score; BPRS-PS = Brief Psychiatric Rating Scale Psychotic Subscale score; SANS = Scale for the Assessment of Negative Symptoms score; CES-D = Centre for Epidemiological Studies - Depression Scale score; Current employment = currently working for pay.

Numbers represent ${ }^{2}$ (i.e., standardized regression coefficients)

$*=p<.05 ; * * *=p<.001$ 


\section{University Library}

\section{- M M N E R VA A gateway to Melbourne's research publications}

Minerva Access is the Institutional Repository of The University of Melbourne

Author/s:

Gardner, A;Cotton, SM;Allott, K;Filia, KM;Hester, R;Killackey, E

Title:

Social inclusion and its interrelationships with social cognition and social functioning in firstepisode psychosis

Date:

2019-06-01

Citation:

Gardner, A., Cotton, S. M., Allott, K., Filia, K. M., Hester, R. \& Killackey, E. (2019). Social inclusion and its interrelationships with social cognition and social functioning in firstepisode psychosis. EARLY INTERVENTION IN PSYCHIATRY, 13 (3), pp.477-487. https:// doi.org/10.1111/eip.12507.

Persistent Link:

http://hdl.handle.net/11343/293777 